DOI: $10.2478 /$ achi-2020-0014

\title{
DEGRADATION OF LEUCOMALACHITE GREEN ON AQUEOUS SOLUTION USING ELECTRON BEAM IRRADIATION
}

\author{
Ha Manh Bui ${ }^{\mathrm{a}^{*}}$, Duy Ngoc Nguyen ${ }^{\mathrm{b}}$
}

${ }^{a}$ Department of Environmental Sciences, Saigon University, 273 An Duong Vuong St., District 5, Ho Chi Minh City 700000, Vietnam

${ }^{b}$ Research and Development Center for Radiation Technology, Vietnam Atomic Energy Institute, 202A, 11 St., Linh Xuan Ward, Thu Duc District, Ho Chi Minh City 700000, Vietnam

\begin{abstract}
Leucomalachite green (LMG) was eliminated using the Electron beam process on an aqueous solution. The study examines the impact of some factors, i.e. initial $\mathrm{pH}$, absorbed dose, $\mathrm{LMG}$ concentration and Hydrogen peroxide $\left(\mathrm{H}_{2} \mathrm{O}_{2}\right)$ concentration on the treatment process. The maximum degradation efficiency of malachite green (98.2\%) was reached at $\mathrm{pH} 6$, absorbed dose of $4 \mathrm{kGy}$, LMG concentration of $4 \mathrm{mg} / \mathrm{L}$ and $\mathrm{H}_{2} \mathrm{O}_{2}$ concentration of $8 \mathrm{mM}$. This environmentally friendly electron beam could be applied to degrade of LMG or other organic compounds on an aqueous solution.
\end{abstract}

Keywords: leucomalachite green; parasiticide; electron beam; hydrogen peroxide.

\section{Introduction}

In Vietnam, aquaculture production is one of the important and biggest sector. In 2015, aquaculture production was valued at 4.26 billion USD, accounting for 6.1 percent of the national Gross Domestic Product

\footnotetext{
* Bui Manh Ha, e-mail: manhhakg@yahoo.com.vn
} 
(GDP), up from 2.2 percent a decade ago. ${ }^{1}$ Over the same period, capture fisheries' share of GDP fell from 5.0 percent to 3.6 percent. The rapid growth of the sector has been a major source of agricultural diversification over the past decade. It is a direct result of adapting operating practices together with a focus on the production of exportable species at increased levels of intensification. However, the use of drugs or pharmaceuticals for treating diseases in this sector could cause a lot of environmental issues. One of the typical drug utilized in this purpose is malachite green and its reduced form, leucomalachite green (LMG), which is highly soluble in water and has long been used in the aquaculture industry as a fungicide, parasiticide, and disinfectant. ${ }^{2}$ LMG is also used extensively for dyeing silk, wool, jute, leather, ceramics, and cotton and as a cytochemical staining agent. ${ }^{3}$ LMG presently is not permitted as a food colouring agent or for use in food fish in the United States (Figure 1); however, it is still used elsewhere in the aquaculture and seafood industries, despite the lack of approval from regulatory authorities and some researcher clasified LMG as a recalcitrant compound. ${ }^{4}$

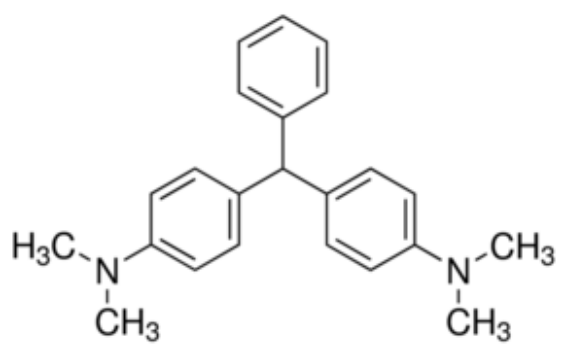

Figure 1. Structure of leucomalachite green.

A variety of techniques, including adsorption, sedimentation, coagulation, electrocoagulation, biological methods, and advanced oxidation processes $^{5-8}$ were used to treat this pollutant. However, these traditional technologies require expensive or large areas of land, which are 
being challenged by urbanization, lack of space and shortcomings. Biological methods, for example, take a long time and can not degrade the recalcitrant compounds. ${ }^{9}$ Besides, recalcitrant compounds are harmful to some microorganisms. ${ }^{10}$ Furthermore, the absorbent cannot be reused in general. $^{8,11}$ Chemical flocculation even causes pollution due to the production of colloids in wastewater. ${ }^{12}$ Common chemical oxidation processes such as chlorine use are slow and need dangerous reactive materials to transport and store. ${ }^{13}$ Another problem is that these methods are not effective enough because of the chemical complexity of the wastewater ${ }^{9}$ Advanced oxidation and oxidation (AOPs) methods such as ozonation, photocatalysis, and Fenton, which are release hydroxyl radical $\left(\mathrm{OH}^{\bullet}\right)$ are very expensive and uneconomical. ${ }^{14}$ Therefore, there should be ways to treat wastewater that consumes appropriate amounts of chemicals and energy, more efficient outputs that meet effluent standards.

Currently, researchers have identified a series of electron beam (EB) -a kind of AOP method- for radioactive disinfection applications. This method can be used to disinfect medical instruments, glassware, as well as to disinfect bottles in the food industry ${ }^{15}$ Additionally; some studies indicate that EB is capable of treating domestic wastewater from organic pollutants, petroleum waste $^{16}$ urban wastewater disinfection, ${ }^{17}$ increasing the biodegradability of textile wastewater, ${ }^{18}$ slaughterhouse wastewater wastewater. $^{19,20}$ Estimating the cost of handling EB compared to conventional methods shows that EB is more expensive than chlorine and less expensive than activated sludge. ${ }^{17}$

Although numerous researches have been conducted on the influence of EB on the degradation of recalcitrant organic compounds, ${ }^{18-20}$ much less is known about EB degradation on LMG and how $\mathrm{H}_{2} \mathrm{O}_{2}$ affects 
the EB process. Therefore, this approach aims to assess the impacts of EB on the degradation of LMG by factors such as initial LMG concentration, initial $\mathrm{pH}$, the concentration of $\mathrm{H}_{2} \mathrm{O}_{2}$ and absorbed dose.

\section{Experimental}

\section{Synthetic solutions}

A stock $100 \mathrm{mg} / \mathrm{L}$ LMG's solution was prepared by dissolving 100,00 mg standard LMG (Sigma-Aldrich) in $1000 \mathrm{~mL}$ sterilized deionized water. Working LMG solutions from 1.0 to $8.0 \mathrm{mg} / \mathrm{L}$ were obtained by serial dilutions of the stock solutions with deionized water. The liquid chromatography (LC, Agilent Technologies, Palo Alto, CA, USA) tandem mass spectrometry (MS/MS, 4000 QTRAP, Applied Biosystems, USA) to monitor transitions $\mathrm{m} / \mathrm{z} 331 \rightarrow 239$ for quantitating LMG . All solvents and other chemicals supplied were analytical grades. The chemical and solutions were protected from light and stored at $4^{\circ} \mathrm{C}$.

\section{Irradiation procedures}

The EB irradiation experiments could be found in our previous study $^{18}$. Briefly, $1000 \mathrm{~mL}$ of LMG solutions with or without $\mathrm{H}_{2} \mathrm{O}_{2}$ containing on the plastic box (thickness $2.5 \mathrm{~cm}$ ) were irradiated with doses from 1.0 to $10 \mathrm{kGy}$ by electron accelerator UERL $-10-15 \mathrm{~S}_{2}(10 \mathrm{MeV}$, $15 \mathrm{~kW}$ ) in Vietnam Atomic Energy Institute, Vietnam. The absorbed doses were measured using dichromate dosimetry (ASTM International, 2004). ${ }^{21}$ Hydrogen peroxide concentration was varied from 1.0 to $4.0 \mathrm{mM}$, while the initial $\mathrm{pH}$ of the samples was adjusted from 3 to 11 . 


\section{Analysis method}

LMG concentrations of samples were analyzed by LC-tandem MS equipped with a turbo spray electrospray (ESI) interface, monitoring transitions $\mathrm{m} / \mathrm{z} 331 \rightarrow 239$ for quantitating $\mathrm{LMG}$. The initial $\mathrm{pH}$ values of the solution were measured using an Inolab $740 \mathrm{pH}$ meter. Results were expressed as the mean of triplicate determinations and all statistical analyses were conducted using Microsoft excel software release 2010 (Microsoft Corp., USA).

\section{Results and Discussion}

\section{Effect of absorbed dose}

In the $\mathrm{EB}$ process, absorbed dose determines the $\mathrm{OH}^{\bullet}$ production rate that could increment the LMG removal capacity. ${ }^{22}$

$$
\mathrm{H}_{2} \mathrm{O} \rightarrow[2.8] \mathrm{OH}^{\bullet}+[2.7] \mathrm{e}_{\mathrm{aq}}^{-}+[0.6] \mathrm{H}^{\bullet}+[0.72] \mathrm{H}_{2} \mathrm{O}_{2}+[2.7] \mathrm{H}_{3} \mathrm{O}^{+}+[0.48] \mathrm{H}_{2}
$$

In order to evaluate the effect of absorbed dose on LMG removal, the experiment was carried out using various absorbed doses from 0 to $10 \mathrm{kGy}$ at $\mathrm{pH} 6$ and $4 \mathrm{mg} / \mathrm{L}$ of LMG without adding $\mathrm{H}_{2} \mathrm{O}_{2}$.

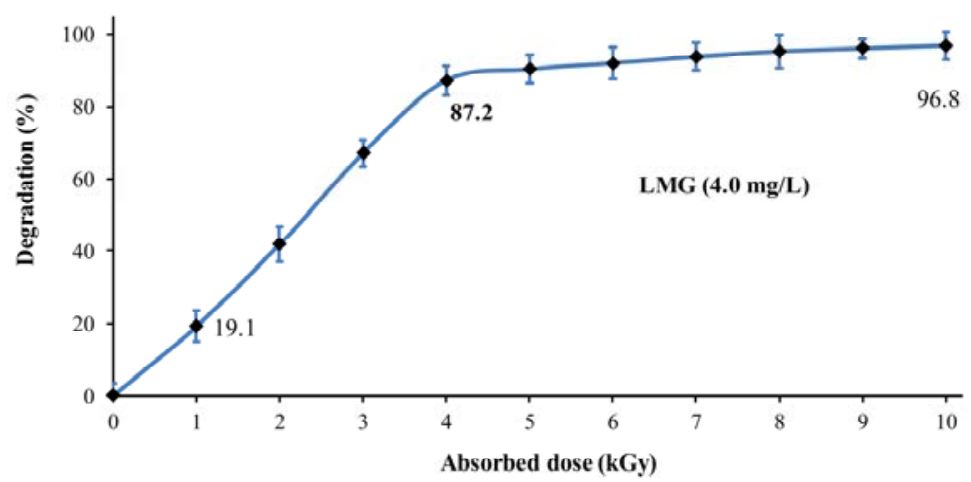

Figure 2. The effect of absorbed dose on the removal efficiencies of leucomalachite green $(\mathrm{pH}=6)$. 
Figure 2 shows the behaviour of LMG removal efficiencies under the impact of the variation of the absorbed dose. The results indicate that the removal efficiencies of $\mathrm{LMG}$ sharp rise from $19.1 \%$ at 1.0 dose to $87.2 \%$ at 4.0 dose and then marginal increase to $96.8 \%$ at 10.0 dose, respectively which means that the final LMG in the treated water decreased from 4.4 to 0.57 and finally $0.14 \mathrm{mg} / \mathrm{L}$, respectively, These results may be due to the $\mathrm{OH}^{\bullet}$ initial rate imcrement and finally attain saturation as reaching equilibrium in LMG solution. ${ }^{22,23}$ Which finding ties well with previous studies of Guo and Shen. ${ }^{24}$ Therefore, the suitable irradiation dose of $4 \mathrm{kGy}$ was chosen for the next experiment.

\section{Effect of the LMG's concentration}

LMG's concentration can play a critical role in the EB process. To investigate the effect of the LMG's concentration on the removal efficiency by EB technique, LMG's concentration is varied from 1 to $8 \mathrm{mg} / \mathrm{L}$, with a fixed absorbed dose (4 kGy) and initial pH (6) without adding $\mathrm{H}_{2} \mathrm{O}_{2}$.

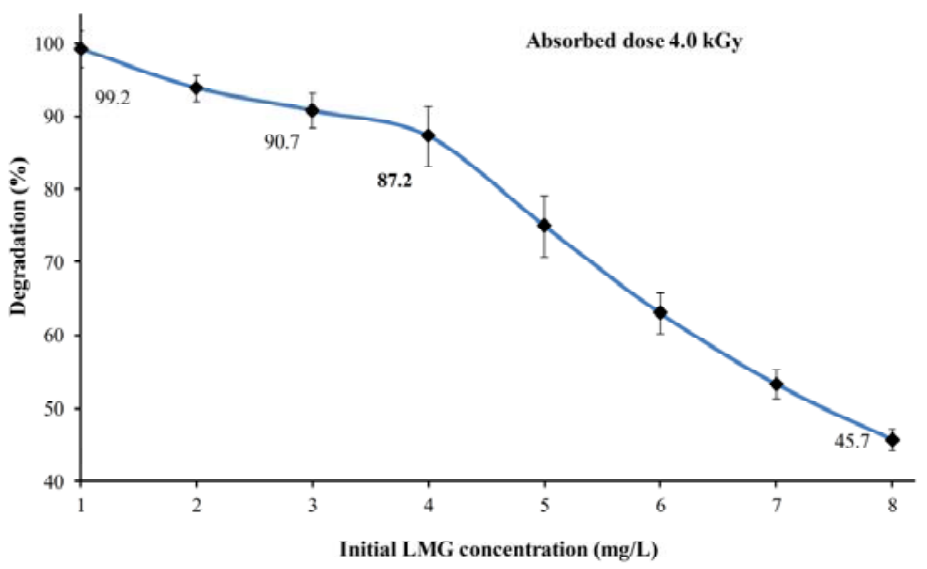

Figure 3. The effect of LMG's concentration on the removal efficiencies with absorbed dose $4 \mathrm{kGy}$ at $\mathrm{pH}=6$. 
The results in Figure 3 show that the LMG degradation rate increased much faster for lower initial LMG concentration-response from 4.0 to $1.0 \mathrm{mg} / \mathrm{L}$. However, beyond $4.0 \mathrm{mg} / \mathrm{L}$, the degradation efficiency was sharply reduced from $87.2(4 \mathrm{mg} / \mathrm{L})$ to $45.7 \%(8 \mathrm{mg} / \mathrm{L})$. The reason may be due to high concentrations of LMG increased intermediate products which compete with LMG to react with hydroxyl radicals and can also become limiting reagents. Consequently, LMG of $4 \mathrm{mg} / \mathrm{L}$ was used in further experiments.

\section{Effect of initial pH}

The effects of initial $\mathrm{pH}$ on the removal of LMG by EB were studied within the range from 4 to 10 . LMG concentrations and absorbed dose were fixed at $4.0 \mathrm{mg} / \mathrm{L}$ and $4.0 \mathrm{kGy}$, respectively, for all the batch experiments, no $\mathrm{H}_{2} \mathrm{O}_{2}$ were added.

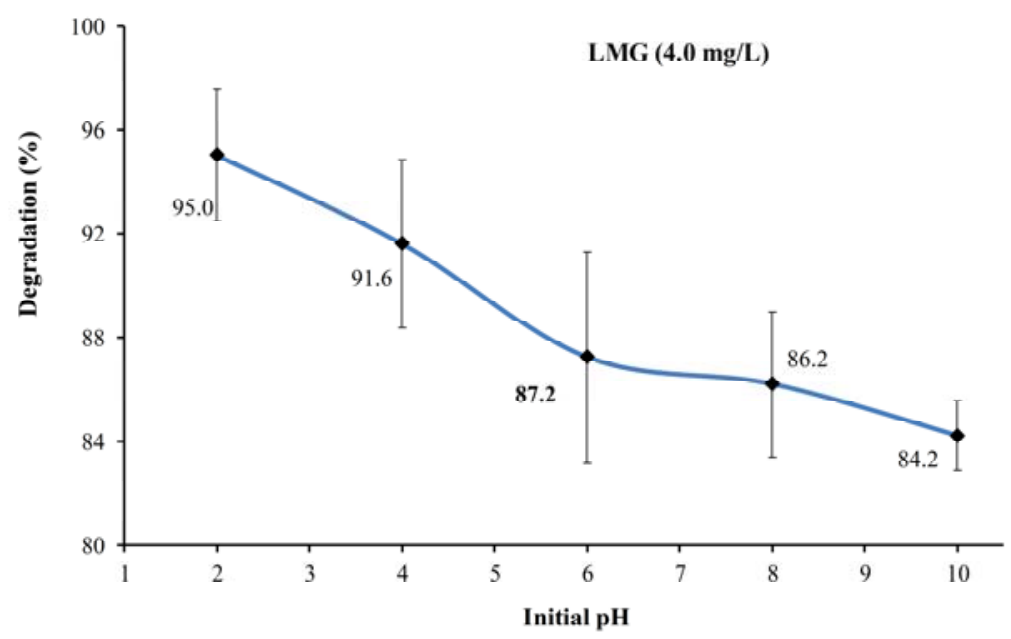

Figure 4. The effect of initial $\mathrm{pH}$ on the removal efficiencies with absorbed dose 4 $\mathrm{kGy}$ and $\mathrm{LMG} 4.0 \mathrm{mg} / \mathrm{L}$.

As can be seen in Figure 4, degradation efficiency slightly decrements with an increment of initial $\mathrm{pH}$ from $1(95.0 \%)$ to $11(84.2 \%)$. This results probably due to the dominant formation of $\mathrm{OH}^{\bullet}$ which could interact with 
LMG at lower $\mathrm{pH}$ value. The findings are consistent with the study of

Dessouki, et al. ${ }^{25}$ for the degradation of pesticides. Although the removal efficiency is predominant at lower $\mathrm{pH}$, however, insignificantly effects on degradation efficiency are recorded within the assayed $\mathrm{pH}$ values (around $10 \%$ ). Moreover, the natural $\mathrm{pH}$ value of $4 \mathrm{mg} / \mathrm{L}$ of $\mathrm{LMG}$ is approximately $6.0(87.2 \%)$, which means there is no cost for addition adjusting $\mathrm{pH}$ chemicals $(\mathrm{NaOH}$ or $\mathrm{HCl})$, which lead the EB process is more economical. Therefore, $\mathrm{pH} 6$ was selected for the next experiment.

\section{Effect of hydrogen peroxide concentration}

A lot of previous studies indicate that $\mathrm{H}_{2} \mathrm{O}_{2}$ could enhance $\mathrm{OH}^{\bullet}$ generation and then improve the organic removal in some kind of wastewater $^{17,18}$ as shown in Equations 2 and 3.

$$
\begin{aligned}
& \mathrm{e}^{-}{ }_{\mathrm{aq}}+\mathrm{H}_{2} \mathrm{O}_{2} \rightarrow \mathrm{OH}^{\bullet}+\mathrm{OH}^{-} \\
& \mathrm{H}^{\bullet}+\mathrm{H}_{2} \mathrm{O}_{2} \rightarrow \mathrm{OH}^{\bullet}+\mathrm{H}_{2} \mathrm{O}
\end{aligned}
$$

The effect of $\mathrm{H}_{2} \mathrm{O}_{2}$ was studied by changing the $\mathrm{H}_{2} \mathrm{O}_{2}$ concentrations from 1.0 to $6.0 \mathrm{mM}$ while keeping initial $\mathrm{pH}$, absorbed dose and LMG concentration constant.

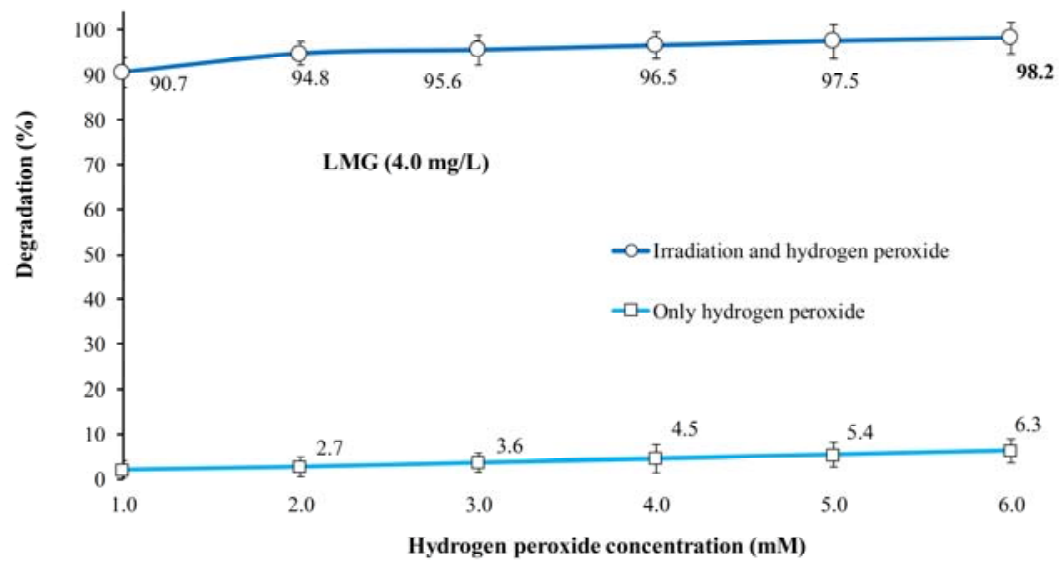

Figure 5. The effect $\mathrm{H}_{2} \mathrm{O}_{2}$ on the removal efficiencies with absorbed dose $4 \mathrm{kGy}$ and LMG $4.0 \mathrm{mg} / \mathrm{L}$ at $\mathrm{pH} 6$. 
The results presented in Figure 5, it was observed that degradation slightly increases with $\mathrm{H}_{2} \mathrm{O}_{2}$ alone $(6.3 \%$ at $6 \mathrm{mM})$ while EB coupled $\mathrm{H}_{2} \mathrm{O}_{2}$ significantly increase removal efficiency from 87.2 (EB alone) to $90.2 \%$ $\left(\mathrm{EB} / 1 \mathrm{mM} \mathrm{H} \mathrm{H}_{2}\right)$ and $98.2 \%\left(\mathrm{~EB} / 6 \mathrm{mM} \mathrm{H} \mathrm{H}_{2} \mathrm{O}_{2}\right.$. The combined effect of $\mathrm{H}_{2} \mathrm{O}_{2}$ and $\mathrm{EB}$ was much higher than the effect of either component or even of the sum of the individual effect. The results again demonstrate that $\mathrm{H}_{2} \mathrm{O}_{2}$ is able to activate EB and produce more $\mathrm{OH}^{\bullet}$ in water, the findings are directly in line with previous reports. ${ }^{17,18}$

\section{Conclusions}

This present work investigates the efficiency of electron beam coupled with $\mathrm{H}_{2} \mathrm{O}_{2}$ performed to the treatment of leucomalachite green in aqueous solution. The experiment was carried out at different leucomalachite green concentration, absorbed dose, $\mathrm{H}_{2} \mathrm{O}_{2}$ concentration and initial $\mathrm{pH}$ values. EB techniques for degradation of $\mathrm{LMG}$ could be favoured at lower initial $\mathrm{pH}$, higher absorbed dose and higher $\mathrm{H}_{2} \mathrm{O}_{2}$ concentration. At the optimum values of the variables ( $4 \mathrm{kGy}$ absorbed dose, $4 \mathrm{mg} / \mathrm{L}$ of LMG, pH 6 and $6 \mathrm{mM}$ of $\mathrm{H}_{2} \mathrm{O}_{2}$ ), almost LMG had been eliminated (98.2\%). However, beyond the optimum value, the further increase in absorbed dose and $\mathrm{H}_{2} \mathrm{O}_{2}$ concentration could lead to the degradation of LMG declining. The results show that electron beam radiation is a promising method for the degradation of organic pollutants in aqueous solutions.

\section{Acknowledgments}

This work was supported by the International Atomic Energy Agency (IAEA) under Project No. F23034 and Saigon University under Project No. CS2019-58. The authors are thankful to VINAGAMMA center for providing necessary conditions during the implementation of this project. 


\section{References}

1. Khanh Nguyen, H. T.; Nang Thu, T. T.; Lebailly, P.; Azadi, H. Economic challenges of the export-oriented aquaculture sector in Vietnam. J. Appl. Aquac. 2019, 31, 367-383.

2. Zhou, X.; Zhang, J.; Pan, Z.; Li, D. Review of methods for the detection and determination of malachite green and leucomalachite green in aquaculture. Crit. Rev. Anal. Chem. 2018, 1-20.

3. Ali, J.; Muthuraman, G. Effective extraction and recovery of malachite green from wastewater using orthochloro benzoic acid. Int. J. Chem. Tech. Res. 2015, 7, 3126-3133.

4. Ayed, L.; Chaieb, K.; Cheref, A.; Bakhrouf, A. Biodegradation of triphenylmethane dye Malachite Green by Sphingomonas paucimobilis. World J. Microbiol. Biotechnol. 2009, 25, 705.

5. Ha, B. M.; Yuan, P. S.; Huong, D. T. G. The use of artificial neural network for modelling coagulation of reactive dyeing wastewater using Cassia Fistula gum. J. Environ. Sci. Manag. 2016, 19, 1-10.

6. Ha, B. M. Modeling the removal of Sunfix Red S3B from aqueous solution by electrocoagulation process using artificial neural network. $J$. Serb. Chem. Soc. 2016, 81, 959-970.

7. Ha, B. M.; Huong, D. T. G.; Cuong, N. D. Applying an artificial neural network to predict coagulation capacity of reactive dyeing wastewater by chitosan. Pol. J. Environ. Stud. 2016, 25, 545-555.

8. Salleh, M. A. M.; Mahmoud, D. K.; Karim, W. A. W. A.; Idris, A. Cationic and anionic dye adsorption by agricultural solid wastes: A comprehensive review. Desalination 2011, 280, 1-13.

9. Pirkarami, A.; Olya, M. E. Removal of dye from industrial wastewater with an emphasis on improving economic efficiency and degradation mechanism. J. Saudi Chem. Soc. 2017, 21, S179-S186.

10. Mani, S.; Chowdhary, P.; Bharagava, R. N., Advances in Carbohydrate Chemistry, Springer Nature, Singapore, 2019, p. 79.

11. Yuan, P. S.; Ha, B. M. The feasibility of cassia fistula gum with polyaluminium chloride for decolorization of reactive dyeing wastewater. J. Serb. Chem. Soc. 2015, 80, 115-125. 
12. Ha, B. M. Decolorization of Suncion Red P-2B Solution by Gamma Co-60 Irradiation in the Presence of Hydrogen Peroxide. J. Adv. Oxid. Technol. 2018, 21, 118-126.

13. Chen, C. M.; Shih, M. L.; Lee, S. Z.; Wang, J. S. Increased toxicity of textile effluents by a chlorination process using sodium hypochlorite. Water Sci. Technol. 2001, 43, 1-8.

14. Bilińska, L.; Gmurek, M.; Ledakowicz, S. Comparison between industrial and simulated textile wastewater treatment by AOPs Biodegradability, toxicity and cost assessment. Chem. Eng. 2016, 306, 550-559.

15. Hayashi, T.; Takahashi, Y.; Todoriki, S. Sterilization of foods with lowenergy electrons ("soft-electrons"). Radiat. Phys. Chem. 1998, 52, 7376.

16. Wojnárovits, L.; Takács, E.; Szabó, L., Advances in Carbohydrate Chemistry, IWA publishing, London, UK, 2018, pp. 79-89.

17. Kurucz, C. N.; Waite, T. D.; Cooper, W. J. The Miami Electron Beam Research Facility: a large scale wastewater treatment application. Radiat. Phys. Chem. 1995, 45, 299-308.

18. Duy, N. N.; Van Phu, D.; Lan, N. T. K.; Duoc, N. T.; Hien, N. Q.; Hiep, B. N.; Han, B. N.; Ha, B. M. Treatment of Real Textile Wastewater Using Electron Beam Irradiation. Acta Chem. Iasi 2019, 27, 303-316.

19. Kim, T. H.; Nam, Y. K.; Lee, M. J. Electron-Beam Irradiation of Livestock Wastewater in the Presence of Natural Zeolite. J. Korean Phys. Soc. 2009, 54, 2109-2114.

20. Cho, J. Y. Evaluation of Degradation of Antibiotic Tetracycline in Pig Manure by Electron Beam Irradiation. Bull. Environ. Contam. Toxicol. 2010, 84, 450-453.

21. ASTM International, Standard practice for use of a dichromate dosimetry system, in, ISO/ASTM 51401: 2003(E), Standards on dosimetry for radiation processing, 2004, pp. 69-75.

22. LaVerne, J. A. OH radicals and oxidizing products in the gamma radiolysis of water. Radiat. Res. 2000, 153, 196-200.

23. Sánchez-Polo, M.; López-Peñalver, J.; Prados-Joya, G.; Ferro-García, M. A.; Rivera-Utrilla, J. Gamma irradiation of pharmaceutical 
compounds, nitroimidazoles, as a new alternative for water treatment. Water Res. 2009, 43, 4028-4036.

24. Guo, F.; Shen, H. Study of gamma irradiation-induced effects on organic pollutants and suspended solids in coking wastewater. Desalin. Water Treat. 2013, 52, 1850-1854.

25. Dessouki, A. M.; Aly, H. F.; Sokker, H. H. The use of gamma radiation for removal of pesticides from wastewater. Czech J. Phys. 1999, 49, $521-533$. 